\title{
A bi-objective integer programming model for locating garbage accumulation points: a case study
}

Un modelo bi-objetivo de programación entera para localizar puntos de acumulación de residuos: un estudio de caso

\author{
Diego Gabriel Rossit (iD) ${ }^{1 *}$, Sergio Nesmachnow (iD) ${ }^{2}$, Jamal Toutouh (iD ${ }^{3}$ \\ ${ }^{1}$ INMABB, Departmento de Ingeniería, Universidad Nacional del Sur(UNS)-CONICET. 1253 Alem Av. C. P. B8000CPB. Bahía Blanca, \\ Argentina. \\ ${ }^{2}$ Facultad de Ingniería, Universidad de la República. 565 Julio Herrera y Reissig Av. C. P. 11300. Montevideo, Uruguay. \\ ${ }^{3}$ MIT Computer Science and Artificial Intelligence Laboratory, Massachusetts Institute of Technology. 32 Vassar St. C. P. MA 02139. \\ Cambridge, USA.
}

\section{CITE THIS ARTICLE AS: \\ D. G. Rossit, S. \\ Nesmachnow and J. Toutouh, "A bi-objective integer programming model for locating garbage accumulation points: a case study", Revista Facultad de Ingeniería Universidad de Antioquia, no. 93, pp. 70-81, Oct-Dec 2019. [Online]. Available: https://www.doi.org/ 10.17533/udea.redin. 20190509}

\section{ARTICLE INFO:}

Received: December 04, 2018

Accepted: April 03, 2019

Available online: May 08, 2019

\section{KEYWORDS:}

Smart cities, municipal solid waste, multiobjetive optimization

Ciudades inteligentes, residuos sólidos urbanos, optimización multiobjetivo
ABSTRACT: Enhancing efficiency in Municipal Solid Waste (MSW) management is crucial for local governments, which are generally in charge of collection, since this activity explains a large proportion of their budgetary expenses. The incorporation of decision support tools can contribute to improve the MSW system, specially by reducing the required investment of funds. This article proposes a mathematical formulation, based on integer programming, to determine the location of garbage accumulation points while minimizing the expenses of the system, i.e., the installment cost of bins and the required number of visits the collection vehicle which is related with the routing cost of the collection. The model was tested in some scenarios of an important Argentinian city that stills has a door-to-door system, including instances with unsorted waste, which is the current situation of the city, and also instances with source classified waste. Although the scenarios with classified waste evidenced to be more challenging for the proposed resolution approach, a set of solutions was provided in all scenarios. These solutions can be used as a starting point for migrating from the current door-to-door system to a community bins system.

RESUMEN: Aumentar la eficiencia en la gestión de los Residuos Sólidos Urbanos (RSU) es crucial para los gobiernos municipales, que son los que generalmente se encargan de la recolección, ya que esta actividad consume un porcentaje importante de sus recursos presupuestarios. La incorporación de herramientas de apoyo a la toma de decisiones puede contribuir a mejorar el sistema de gestión de RSU, especialmente reduciendo los costos de inversión requeridos. Este artículo propone una formulación metemática, basada en programación entera, para determinar la localización de puntos de acumulación de residuos minimizando los costos del sistema, incluyendo tanto el costo de instalación de los contenedores como la cantidad de visitas necesarias del vehículo de recolección, lo cual está relacionado con los costos de la logística de recolección. El modelo se aplicó en un conjunto de escenarios reales de una importante ciudad argentina que todavía utiliza un sistema de puerta a puerta, incluyendo tanto intancias que donde los residuos son recolectados $\sin$ clasficar, como actualmente se realiza en esta ciudad, como instancias que incorporan la clasificación en origen de los mismos. A pesar de que los escenarios con clasificación en origen resultaron más desafiantes para el algoritmo de resolución propuesto, se obtuvieron un conjunto de soluciones factibles para todos los escenarios planteados. Estas soluciones pueden ser utilizadas como un punto inicial para migrar desde un sistema de puerta a puerta a uno de contenedores comunitarios.

\section{Introduction}

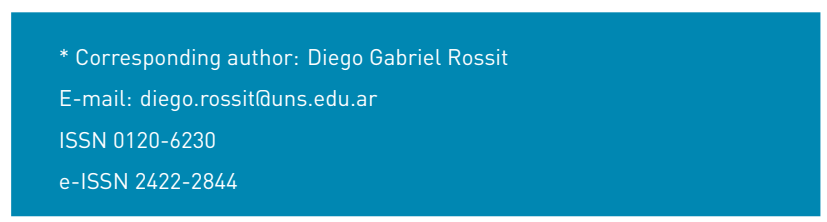

In recent years, the paradigm of smart cities has arisen as a strategy from governments and decision-makers to improve the quality of the public services provided to the 
citizens. Despite being a fuzzy concept, Chourabi et al. states that "one way to conceptualize a smart city is as an icon of a sustainable and livable city" [1]. Moreover, these authors identify a comprehensive set of factors that are essential to understand smart city initiatives and projects.

These are: management and organization, technology, governance, policy, people and communities, the economy, built infrastructure, and the natural environment. While the related literature about some of these factors, such as technology applications, is relatively extensive, some other factors, such as the one in which is focused this article, i.e., management and organization, have not been thoroughly studied yet [1]. Thus, smart city initiatives have reported a varied set of urban services in public transportation $[2,3]$, health services [4], and energy management [5]. Municipal Solid Waste (MSW) management is another field in which smart cities initiatives have been effectively applied to mitigate the environmental and economic problems [6-8].

This article is an extension of our previous conference article [7] presented at the Ibero-American Congress of Smart Cities ICSC-CITIES 2018 and provides an optimization model to support the decision-making process in the MSW system. This model addresses the problem of selecting the proper location of garbage community bins for a city with the aim of migrating from a door-to-door collection to a community bins system that is expected to be more efficient in terms of logistic costs [8]. Particularly, a case of study of the city of Bahía Blanca, which is an important medium size city in the South of Argentina, is addressed in this work. The objective of migrating from the current door-to-door collection system to a community bins based one, where the citizens have to carry their waste to certain bins, is usually among the plans of the local authorities for reducing the collection complexity. Solutions that contribute to reduce logistic costs are of particular interest for Argentinian cities since these costs are extremely high in this country [9]. Although nowadays citizens of Bahía Blanca do not perform source classification of waste, considering that an efficient collection network of waste bins can encourage recycling [10], the model is applied on both scenarios with unsorted waste and a set of more complex scenarios where specific bins for different types of waste are installed.

As stated, using a community bins system has certain advantages over the door-to-door system. However, the location of bins in an urban area is not a trivial problem if it is supposed to be efficient [11]. This is mainly due to the characteristic of the underlying optimization problem, which is a variation of the Capacitated Facility Location Problem (CFLP). CFLP has been proven to be NP-hard through a reduction to a 3-dimensional matching problem (3DM) [12]. Besides, finding the ubity of garbage accumulation points have an extra difficulty associated with the conflicting relationships between the several criteria that are expected to be taken into account during the process. For example, waste bins should not be very far from the generators since this would provoke its misuse. On the other hand, a proper scheduling of collection vehicles should be established to avoid bins overflowing. Moreover, the frequency of garbage collection has an impact on the necessary bin capacity.

The article is structured as follows. In Section 2, the mathematical formulation of the target problem and the main related work is presented. Section 3 describes the solution approach used for solving the proposed model. Then, in Section 4 the scenarios in which the model was applied and the analysis of the main results are presented. Finally, Section 5 outlines the main conclusions and formulates the lines for future work.

\section{Problem description}

This Section describes the the problem addressed in this article. In Section 2.1 the conceptual model is described. In Section 2.2 the proposed mathematical formulation is presented. Finally, in Section 2.3 a review of relevant works from the related literature is performed.

\subsection{Problem model}

The problem considered in this article consists in locating Garbage Accumulation Points (GAP) while optimizing two different criteria, both related to the expenses of the system. The first criteria is to minimize the total investment cost, i.e., the purchase cost of each individual bin. The second criteria is to enhance the 'autonomy' of the GAPs. Autonomy is related to the number of days that a GAP can wait between two consecutive visits of the collection vehicle (to empty the bins). Naturally, the larger number of bins a GAP has, the larger the storage capacity and the larger the period of autonomy. However, having many bins implies a large investment to purchase the bins. The distribution and capacity of GAPs has a clear impact on posterior collection costs [13]. Since logistic costs are of particularly high in Argentina [9], reducing the frequency a GAP has to be visited is a valuable feature for Argentinians decision makers. Moreover, the possibility to reduce the installed capacity of the GAPs land, therefore, the initial investment cost of the network of bins) by increasing the collection frequency is a feature of the target problem that differentiates it from the classical single-objective CFLP problem [12]. Another important characteristic of GAP location is facilitating the accessibility for users. Therefore, a restriction to forbid that a generator has to transport their garbage more than a given threshold distance is included. 


\subsection{Mathematical formulation}

The problem can be modeled as an Integer Programming (IP) model by considering the following sets:

- A set $I=\left\{i_{1}, \ldots, i_{|I|}\right\}$ of potential GAPs for bins.

- A set $P=\left\{p_{1}, \ldots, p_{|P|}\right\}$ of generators.

- A set $H=\left\{h_{1}, \ldots, h_{|H|}\right\}$ of waste fractions.

- A set $J=\left\{j_{1}, \ldots, j_{|J|}\right\}$ of bin types.

- A set $Y=\left\{y_{1}, \ldots, y_{|Y|}\right\}$ of collection frequencies profiles.

The relevant parameters for the model associated with these sets are:

- $E s_{i}$ is the available space for installing bins in GAP $i$.

- $d_{p i}$ is the distance from generator $p$ to GAP $i$.

- $D$ is the maximum allowable distance between any generator in $P$ and its assigned GAP.

- $b_{h p}$ is the amount of waste produced by generator $p$ (in volumetric units) of waste fraction $h$ on a daily basis.

- $\operatorname{cin}_{j}$ is the purchase price of bin type $j$.

- $C_{j}$ is the capacity of type of bin type $j$.

- $e_{j}$ is the required space for its installation of type of bin type $j$.

- $a_{y}$ is the number of days among two consecutive visits of the collection vehicle for collection frequency $y$.

The model is described in Equations 1-11, using the following variables:

- $t_{j h i}$ is the number of bins of type $j$ for the waste fraction $h$ installed in GAP $i$.

- $x_{p i}$ is 1 if generator $p$ is assigned to GAP $i$ and 0 otherwise

- $f_{\text {hiy }}$ is 1 if frequency profile $y$ (defined by parameter $\left.a_{y}\right)$ is used for waste fraction $h$ for GAP $i$ and 0 otherwise.

$$
\begin{gathered}
\min \sum_{\substack{j \in J \\
h \in H \\
i \in I}}\left(t_{j h i} c i_{j}\right) \\
\min \frac{\sum_{\substack{h \in H \\
i \in I \\
y \in Y}}\left(\frac{f_{h i y}}{a_{y}}\right)}{|I||H|}
\end{gathered}
$$

Subject to

$$
\begin{gathered}
\sum_{i \in I}\left(x_{p i}\right)=1, \forall p \in P \\
\sum_{\substack{j \in J \\
h \in H}}\left(t_{j h i} e_{j}\right) \leq E s_{i}, \forall i \in I \\
\sum_{\substack{p \in P \\
y \in Y}}\left(b_{h p} x_{p i} f_{h i y} a_{y}\right) \leq \sum_{j \in J}\left(c^{\prime} a p_{j} t_{j h i}\right), \\
\forall i \in I, h \in H \\
\sum_{y \in Y} f_{h i y} \leq 1, \forall i \in I, h \in H \\
|P| \sum_{y \in Y} f_{h i y} \geq \sum_{p \in P} x_{p i}, \forall i \in I, h \in H \\
d_{p i} x_{p i} \leq D, \forall p \in P, i \in I \\
x_{p i} \in\{0,1\}, \forall p \in P, i \in I \\
f_{h i y} \in\{0,1\}, \forall h \in H, i \in I, y \in Y \\
t_{j h i} \in \mathbb{Z}_{0}^{+}, \forall j \in J, h \in H, i \in I
\end{gathered}
$$

There are two objective functions. Equation (1) is the cost of the installed community bins and Equation (2) is the average collection frequency of the set of GAPs (hereafter $O b j_{c}$ and $O b j_{f}$, respectively). Regarding constraints, Equation (3) establishes that each generator should be assigned to a GAP. Equation (4) ensures that the occupied space by the bins is not larger than the available space in a GAP. Equation (5) limits the amount of each type of waste assigned to a GAP to the capacity of the installed bins for that type of waste in that GAP. Equation (6) forces that at most one frequency profile is chosen for each type of waste in a GAP. Equation (7) establishes that if a generator is assigned to a GAP, that GAP has a collection frequency profile for each type of waste. Equation (8) restricts the maximum distance between a generator and the assigned GAP to a certain threshold distance. Equations (9) and (10) define the binary nature of the variables $x_{p i}$ and $f_{\text {hiy }}$. Equation (11) defines that $t_{j h i}$ is a non-negative integer variable.

The proposed model formulation is not linear due to the product present in Equation (5). Although linearization is a common practice to handle nonlinear problems [14], the benefits of using linear equivalent forms can be offset if the transformation increases the number of integer variables since this is generally an indicator of the difficulty of the problem [15]. This is why the linearization technique that was firstly proposed in [15] was later improved in [16] in order to avoid increasing the number of integer variables. According to [16], the continuous variable $u_{\text {phiy }}$ has to be added to the model and, in terms of the problem addressed in this article, its definition is $u_{p h i y}=x_{p i} f_{h i y}-f_{h i y}+U_{x_{p i}}\left(1-x_{p i}\right)$, where $U_{x_{p i}}$ (2) is the upper bound of the binary variable $x_{p i}$ (i.e., 1). Then, Equation (5) can be replaced by Equations (12)-(16) to build a linear model and, thus, the linear equivalent 
formulation of the model is composed by Equations (1)-(4) and (6)-(16).

$$
\begin{gathered}
\sum_{\substack{p \in P \\
y \in Y}}\left[b_{p h} a_{y}\left(u_{\text {phiy }}+f_{\text {hiy }}-1+x_{p i}\right) \leq \sum_{j \in J}\left(\operatorname{cap}_{j} t_{j h i}\right)\right. \\
\forall i \in I, h \in H \\
u_{\text {phiy }} \geq 1-x_{p i}-f_{\text {hiy }}, \\
\forall p \in P, h \in H, i \in I, y \in Y \\
u_{\text {phiy }} \leq 1-f_{\text {hiy }}, \forall p \in P, h \in H, i \in I, y \in Y \\
u_{\text {phiy }} \leq 1-x_{p i}, \forall p \in P, h \in H, i \in I, y \in Y \\
u_{\text {phiy }} \geq 0, \forall p \in P, h \in H, i \in I, y \in Y
\end{gathered}
$$

Equation (8) can be deleted if only relevant variables $x_{p i}$ are considered, i.e., those for which the distance between the generator $p$ and the GAP $i$ is smaller than $D$ and, therefore, an assignment generator-GAP is possible. This preprocessing strategy was used for enhancing the capacity of the model in the experimentation part of this work (Section 4).

\subsection{Related work}

Few articles have addressed the GAPs location problem using exact methods.

In [17], the problem of locating bins in the city of Coimbra, Portugal, was solved considering four different objectives to minimize: the total cost of the system, the average distance between a generator and its assigned bin, and the number of generators within the "push" and "pull" thresholds distances of an open candidate site. These lasts two objectives are related to the semi-obnoxiousness of the GAPs since citizens do not want waste bins very near to reduce inconvenient environmental costs but neither very far to reduce the transportation costs. The authors used the goal programming and the weighted sum to obtain a set of multiobjective solutions.

A similar problem was solved in [18], in which the $\varepsilon$-constraint method was applied while optimizing two objectives: the total investment cost and a novel "dissatisfaction function" that takes into account the semi-obnoxiousness of the waste bins.

In [19], three different monobjective models to solve the GAPs location problem in Hsinchu, Taiwan, were presented. These models are compared according to the average distance between generators and assigned bins. In [20], the problem of sizing the capacity of the GAPs with the aim of minimizing the installment costs inside a more generic model that also considers the routing scheduling of collection vehicle was solved using CPLEX. Similarly, in [21], the problem of locating GAPs was solved with CPLEX in a general framework that also defines the routing plan.

In [22], an integer model that minimizes the total number of opened GAPs in different scenarios of the city of Nardò, Italy, was presented. A modified version of this model, that prevents an opened GAP from having incompatible bins (i.e., bins that require a different vehicle to be emptied) was applied in [23]. This modification simplifies the posterior collection logistics since no GAP has to be visited by more than one type of vehicle.

Since the facility location problems are known to be NP-hard, several authors have addressed the GAPs location problem them heuristically [24]. For example, our previous work [11] proposed a set of PageRank heuristics and metaheuristics to solve the GAP location problem in some scenarios of the city of Montevideo considering the objectives of minimizing the investment cost and maximizing the collected garbage. In [25], a two-phase heuristic that firstly locates the GAP in the urban network and, then, determines the size of the bins that are going to be assigned to those GAPs is presented. In [26], a fuzzy multi-objective genetic algorithm to solve the recycling drop-off sites allocation and routing collection in Kaohsiung, Taiwan, is proposed.

In Argentina, as is common in developing countries [27], the application of smart cities initiatives in MSW management is quite scarce. Moreover, although there are a few proposals for improving routing collection plans in MSW management $[8,28-30]$, there are little applications that deal with waste bins location.

In [31] weighted sum is compared with the augmented epsilon-constraint method (AUGMECON) to solve similar scenarios. There are still opportunities to contribute to improve collection network in Argentina through the application of decision support systems, which can help to alleviate the pressure over local governments which are the ones responsible for MSW management [32].

The research reported in this article contributes with a mathematical formulation for solving the problem of locating GAPs while considering the objective of maximizing the autonomy of the GAPs, through the frequency objective as a way of bounding the posterior collection costs. This objective is valuable since it considers the routing cost of the posterior stage of the MSW system, the collection of the waste. As far as we are concerned, the visit frequency of the GAPs has been considered only in the previous integral approach performed in [20] for a sizing-routing problem. 
However, in the mathematical formulation presented in [20], the assignment of generators to GAPs is not performed. Through this feature, in the model presented in Section 2.2, a potential GAP can remain unopened li.e., no bin is installed) if the nearby generators are assigned to another opened GAP that is within the maximum allowable walking distance. Furthermore, in this article a real case of the Argentinian city of Bahía Blanca is solved.

\section{Solution approach: an adaptation of the augmented $\varepsilon$-constraint method}

The proposed solution approach is based on the augmented $\epsilon$-constraint method (AUGMECON). AUGMECON was first presented in 2009 [33] and later improved in [34], in order to address some of the drawbacks of the traditional $\epsilon$-constraint approach, originally developed in [35]. One of the main highlights of AUGMECON is that it successfully reduces the required computing time to solve complex problems, through the avoidance of weakly efficient or repeated solutions.

AUGMECON requires as input the efficient range of the objective functions, i.e., the nadir and ideal values that each objective assumes within the Pareto front. For the problem studied in this article, since there are only two objectives involved, a single objective optimization approach can be used to find the nadir and ideal value of each objective, as proposed in [36].

However, in bicriteria optimization problems, the ranges obtained using single objective optimization are the efficient ranges of each objective only if there are no alternative solutions [37]. Mavrotas proposed computing the nadir and ideal values of the objectives over the efficient set using lexicographic optimization [33]. Nonetheless, lexicographic optimization evidenced highly time consuming for the problem addressed in this paper. This approach roughly consists in optimizing the set of criteria sequentially providing that the already optimized criteria in the previous runs do not get a worse value in the subsequent runs. In a bicriteria problem, as is the case of this paper, basically this implies an optimization process composed of two stages. The first stage consists of solving a plain single objective optimization for one of the objectives and the second stage consists of solving a second problem to optimize the second criteria subjected to not deteriorating the first criteria, which is added as a constraint in this second model. Therefore, this second stage is a more constrained problem than directly optimizing the second criteria in a single objective fashion and, thus, can only be equally (if not more) difficult to solve than the single objective model.
To overcome this efficiency problem, this article proposes to use a less computational expensive procedure to approximate the efficient range of the objectives, using weighted sum to 'filter' the single objective optimization as was developed in [38]. In the first stage, single objective optimization is applied to obtain an initial extreme solutions for each criteria. However, since these solutions are probable to be inefficient [37], in a second stage, a largely unbalanced vector of weights is used to improve the estimation; the objective function is strongly biased towards the criteria that is optimized but the second criteria still has a small positive weight in order to avoid inefficient solutions. If $K$ is the set of optimization criteria and $t \in K$ is the criteria to be optimized, then the objective function when optimizing $t$ is:

$$
w_{t} \frac{O b j_{t}-O b j_{t^{b}}}{O b j_{t^{w}}-O b j_{t^{b}}}+\sum_{k \in K, k \neq t} w_{k} \frac{O b j_{k}-O b j_{k^{b}}}{O b j_{k^{w}}-O b j_{k^{b}}}
$$

where $w_{t}>w_{k}>0, \forall k \in K, k \neq t$. Therefore, conversely to lexicographic optimization, this approach does not increase the original set of constraints of the problem. Moreover, this strategy has a relevant difference with the previous similar approach used in [17]. In [38], the values of the criteria in the weighted sum are normalized with the results of the single objective optimization in order to make this bias significant since criteria have different measure units and, thus, their ranges may have different absolute values.

The next section evaluates the three studied approaches to estimate the efficient ranges of the criteria: single objective optimization, biased weighted sum, and lexicographic optimization.

\section{Experimental analysis}

This section describes the experimental analysis of the proposed approach for GAP location problems. Section 4.1 presents the development and execution platform. The real scenarios considered in the experiments are described in Section 4.2. In Section 4.3 the numerical results are reported. Finally, in Section 4.4 the analysis of the results in the terms of the problem is outlined.

\subsection{Development and execution platform}

The experimental analysis was performed on a Core i7 processor, with 16 GB of RAM memory, in a Windows 10 environment. The problem was modeled in $\mathrm{C}++$ and the resolution was performed with the parallel mode of CPLEX 12.7.1. as the IP solver through the use of Concert Technology to link Visual Studio $\mathrm{C}++$ and CPLEX. 


\subsection{Scenarios: the city of Bahía Blanca}

Bahía Blanca is a city of about 300,000 inhabitants located in the South of Argentina, being an important port and industrial center of the country. Its MSW system is based on a door-to-door system where the collection vehicle has to visit every dwelling to collect the waste. In general, the collection is performed every day except on Sundays. The majority of this waste is deposed in a landfill that it is near to the city. The scenarios considered in this paper are based on an important neighborhood called "Barrio Universitario", which is a densely populated area of about $730 \mathrm{~m}^{2}$ and 7,900 inhabitants. This neighborhood is shown in Figure 1. As regard to the input data for the model presented in Section 2.2, the garbage generation rate $\left(b_{p h}\right)$ is retrieved from a report that considered the particular characteristics of this city [39]. The density of garbage, which is required to estimate the capacity of the bins in kilograms of waste, was taken from a recent study carried out in Argentina [40].

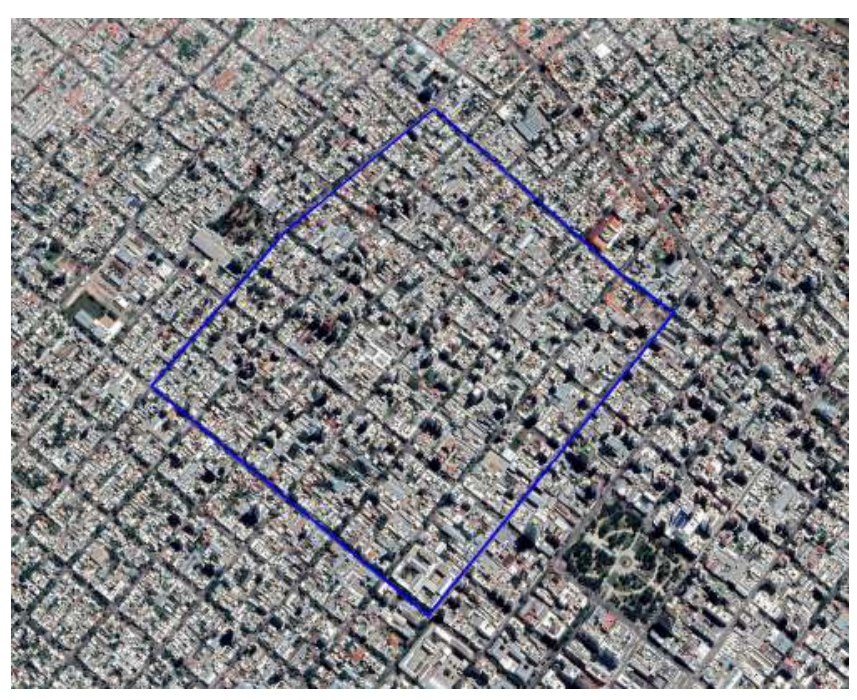

Figure 1 Studied area (“Barrio Universitario”) in Bahía Blanca. Base image: Google Earth Pro 7.3.1

The population density (per square block) was obtained by analyzing the information of the Argentinian national census [41]. The set of frequency profiles is composed of three alternatives (i.e., $|Y|=3$ ). If a GAP is opened, it can be emptied either every day $\left(a_{y}=1\right)$, every two days $\left(a_{y}=2\right)$ or every three days $\left(a_{y}=3\right)$. Regarding to the bin types, three different classes of bins are considered (i.e., $|J|=3$ ). These are $j_{1}, j_{2}$, and $j_{3}$. The associated parameters of these three classes are: capacity $\left(\mathrm{cap}_{j}\right)$ of 1,2 , and $3 \mathrm{~m}^{3}$; required space $\left(e_{j}\right)$ of 1,2 , and $3 \mathrm{~m}^{2}$; and installation cost $\left(\mathrm{cin}_{j}\right)$ of 100, 180, and 250 monetary units, respectively. The available space in a GAP to install bins $\left(E s_{i}\right)$ is equal to $5 \mathrm{~m}^{2}$. Parameter $D$ was set to 250 $m$ as in [17]. Following a usual approach in the related literature, nearby generators are grouped in clusters, assuming a similar behavior between elements in each cluster [17]. The generators in the area of study were clustered in eighty-eight groups (i.e., $|P|=88$ ). In general, each group contains the generators that live in the same block. However, when a block was larger than $150 \mathrm{~m}$, two groups were formed, each one containing half of the generators of the block (see Figure 2). The location of each group it is also a potential place for locating a GAP (i.e., $|I|=88$ ).

The spatial information was organized using QGIS 2.18.6 and the urban walking distances $\left(d_{p i}\right)$ were calculated through an adapted version of the osmar package of $R$ developed in [42] that is able to calculate walking distances. This package retrieves information directly from OpenStreetMap (https : //www . openstreetmap.org/).

Three different generations rates were considered in the experiments. The normal scenario, that considers the waste generation rate $\left(b_{h p}\right)$ estimated by the authorities [39], the demanding scenario, and the undemanding scenario, with generation rates $20 \%$ larger and $20 \%$ smaller than the one defined in the normal scenario, respectively. These $20 \%$ of increment and reduction in the normal waste generation rate are in line with the variations along the year presented in the surveys provided by the practitioners. Then, as mentioned, two variants for each scenario are considered: without source classification of waste (i.e., $|H|=1$ ) and with a classification in two different fractions: dry and humid waste (i.e., $|H|=2$ ), as it is common practice in other Argentinian cities [43]. Therefore, six different instances were solved: three considering waste source classification with normal, low and high generation rates, and three without considering waste source classification considering, again, normal, low and high generation rates.

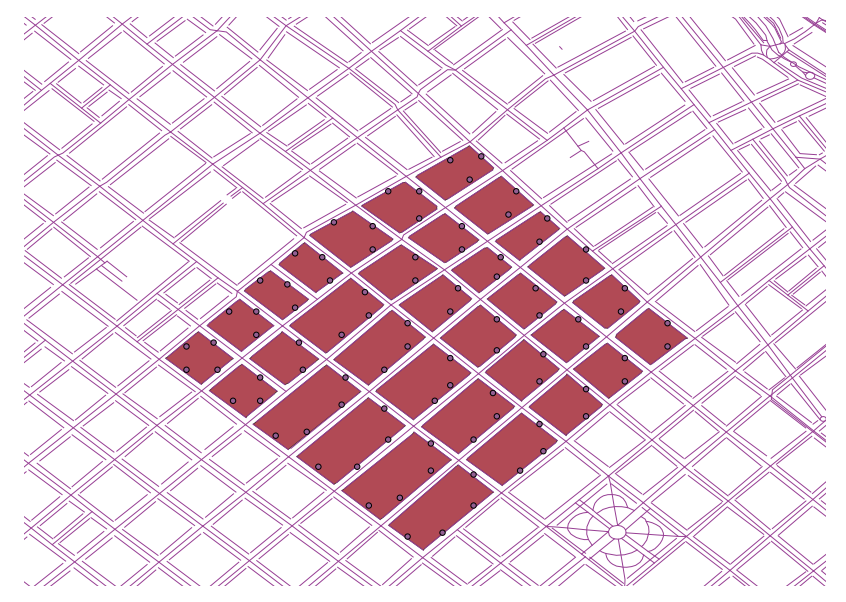

Figure 2 Location of potential GAPs in the studied area ("Barrio Universitario" in Bahía Blancal 


\subsection{Numerical results}

In this Section the results of the application of the methods to approximate the extreme values of the objectives and the AUGMECON to the proposed scenarios are presented.

In regard to the approximation of the extreme values, Tables 1 and 2 report the results of calculating the objectives ranges with single objective optimization, biased weighted sum, and lexicographic optimization for the three studied scenarios with unclassified waste and the three scenarios with classified waste respectively. The tables present the method that was used, the optimized objective, the obtained values of both objectives, and the execution time. The optimized objective in the biased weighted sum refers to the objective with the largest weight, while in lexicographic optimization refers to the criteria taken into account in the first stage of the optimization process. Single objective optimization is the previous step for applying the weighted sum and constitutes the first stage of lexicographic optimization. The execution times reported in Tables 1 and 2 for weighted sum and lexicographic optimization do not include the execution time of the single objective optimization.

Table 1 Extreme values of the objectives of unclassified scenarios

\begin{tabular}{|c|c|c|c|c|}
\hline Method & $\begin{array}{l}\text { Optimized } \\
\text { objective }\end{array}$ & $O b j_{c}$ & $O b j_{f} \mathbf{l}^{*} \mathbf{l}$ & $\begin{array}{c}\text { Execution } \\
\text { time (s) }\end{array}$ \\
\hline \multicolumn{5}{|c|}{ Normal scenario } \\
\hline \multirow{2}{*}{$\begin{array}{l}\text { Single objective } \\
\text { optimization }\end{array}$} & $O b j_{c}$ & 3880 & $0.6875(0.3915)$ & 4205.94 \\
\hline & $O b j_{f}$ & 44000 & $0.1042(0.2578)$ & 4267.95 \\
\hline \multirow{2}{*}{ Weighted sum } & $O b j_{c}$ & 3880 & $0.1819(0.3857)$ & 4204.16 \\
\hline & $O b j_{f}$ & 5710 & $0.1042(0.3857)$ & 4202.16 \\
\hline \multirow{2}{*}{$\begin{array}{l}\text { Lexicographic } \\
\text { optimization }\end{array}$} & $O b j_{c}$ & 3880 & $0.1819(0.3857)$ & 4209.72 \\
\hline & $O b j_{f}$ & \multicolumn{3}{|c|}{ No feasible solution found } \\
\hline \multicolumn{5}{|c|}{ Demanding scenario } \\
\hline \multirow{2}{*}{$\begin{array}{l}\text { Single objective } \\
\text { optimization }\end{array}$} & $O b j_{c}$ & 4710 & $0.5190(0.4567)$ & 4260.51 \\
\hline & $O b j_{f}$ & 44000 & $0.1269(0.2512)$ & 4204.70 \\
\hline \multirow{2}{*}{ Weighted sum } & $O b j_{c}$ & 4710 & $0.2045(0.4033)$ & 4206.09 \\
\hline & $O b j_{f}$ & 8040 & $0.1269(0.2694)$ & 4208.31 \\
\hline \multirow{2}{*}{$\begin{array}{l}\text { Lexicographic } \\
\text { optimization }\end{array}$} & $O b j_{c}$ & 4710 & $0.1932(0.3948)$ & 4207.41 \\
\hline & $O b j_{f}$ & \multicolumn{3}{|c|}{ No feasible solution found } \\
\hline \multicolumn{5}{|c|}{ Undemanding scenario } \\
\hline \multirow{2}{*}{$\begin{array}{l}\text { Single objective } \\
\text { optimization }\end{array}$} & $O b j_{c}$ & 3140 & $0.3182(0.5326)$ & 4267.95 \\
\hline & $O b j_{f}$ & 44000 & $0.0833(0.1846)$ & 4205.94 \\
\hline \multirow{2}{*}{ Weighted sum } & $O b j_{c}$ & 3140 & $0.1591(0.3658)$ & 4200.72 \\
\hline & $O b j_{f}$ & 7230 & $0.0833(0.1846)$ & 4230.24 \\
\hline \multirow{2}{*}{$\begin{array}{l}\text { Lexicographic } \\
\text { optimization }\end{array}$} & $O b j_{c}$ & 3140 & $0.1061(0.3038)$ & 4209.7 \\
\hline & $O b j_{f}$ & \multicolumn{3}{|c|}{ No feasible solution found } \\
\hline
\end{tabular}

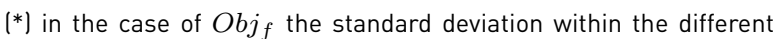
GAPs is reported inside the parenthesis
According to the results in Tables 1 and 2, lexicographic optimization was not able to find a feasible solution for the scenarios when the order of the optimized objectives was first $O b j_{c}$ and then $O b j_{f}$ within the time limit. The main reason for this might be the aforementioned characteristic of the lexicographic approach, i.e., the second stage is a more constrained model. In this case, the single objective problem of minimizing $O b j_{f}$ plus an additional constraint prevents the deterioration of $O b j_{c}$. Therefore, for the proposed scenarios, this enlarged problem seems to be harder to solve than the straightforward single objective optimization of $O b j_{f}$, which was already a NP-hard CFLP. Thus, the efficiency of the solver to obtain feasible solutions is reduced. Furthermore, this ordering of objectives is more challenging for the solver than when $O b j_{f}$ is in the first stage: when $O b j_{f}$ is optimized first CPLEX generally finds a feasible solution within the time limit lexcept for the demanding scenario with classified waste).

Table 2 Extreme values of the objectives of classified scenarios

\begin{tabular}{|c|c|c|c|c|}
\hline Method & $\begin{array}{l}\text { Optimized } \\
\text { objective }\end{array}$ & $\boldsymbol{O} b j_{c}$ & $\left.\boldsymbol{O b j _ { f }} \mathbf{l}^{*}\right)$ & $\begin{array}{c}\text { Execution } \\
\text { time (s) }\end{array}$ \\
\hline \multicolumn{5}{|c|}{ Normal scenario } \\
\hline $\begin{array}{l}\text { Single objective } \\
\text { optimization }\end{array}$ & $\begin{array}{l}O b j_{c} \\
O b j_{f}\end{array}$ & $\begin{array}{l}4800 \\
43710\end{array}$ & $\begin{array}{l}0.4320(0.2833) \\
0.1193(0.2479)\end{array}$ & $\begin{array}{l}4282.75 \\
4206.58\end{array}$ \\
\hline Weighted sum & $\begin{array}{l}O b j_{c} \\
O b j_{f}\end{array}$ & $\begin{array}{l}4800 \\
9080\end{array}$ & $\begin{array}{l}0.1932(0.4190) \\
0.1193(0.2673)\end{array}$ & $\begin{array}{l}4209.38 \\
4208.33\end{array}$ \\
\hline $\begin{array}{l}\text { Lexicographic } \\
\text { optimization }\end{array}$ & $\begin{array}{l}O b j_{c} \\
O b j_{f}\end{array}$ & ${ }^{4800}$ & $\begin{array}{c}0.1932(0.4190) \\
\text { Vo feasible solutior }\end{array}$ & $\begin{array}{l}4204.33 \\
\text { found }\end{array}$ \\
\hline \multicolumn{5}{|c|}{ ing scenario } \\
\hline $\begin{array}{l}\text { Single objective } \\
\text { optimization }\end{array}$ & $\begin{array}{l}O b j_{c} \\
O b j_{f}\end{array}$ & $\begin{array}{c}5640 \\
43610\end{array}$ & $\begin{array}{l}0.4594(0.8152) \\
0.1477(0.2518)\end{array}$ & $\begin{array}{l}4202.23 \\
4204.70\end{array}$ \\
\hline Weighted sum & $\begin{array}{l}O b j_{c} \\
O b j_{f}\end{array}$ & $\begin{array}{c}5650 \\
11180\end{array}$ & $\begin{array}{l}0.2159(0.4114) \\
0.1477(0.2578)\end{array}$ & $\begin{array}{l}4215.83 \\
4206.39\end{array}$ \\
\hline $\begin{array}{l}\text { Lexicographic } \\
\text { optimization }\end{array}$ & $\begin{array}{l}O b j_{c} \\
O b j_{f}\end{array}$ & \multicolumn{3}{|c|}{$\begin{array}{l}\text { No feasible solution found } \\
\text { No feasible solution found }\end{array}$} \\
\hline \multicolumn{5}{|c|}{ Undemanding scenario } \\
\hline $\begin{array}{l}\text { Single objective } \\
\text { optimization }\end{array}$ & $\begin{array}{l}O b j_{c} \\
O b j_{f}\end{array}$ & $\begin{array}{c}3890 \\
43590\end{array}$ & $\begin{array}{l}0.4422(0.2500) \\
0.0900(0.2819)\end{array}$ & $\begin{array}{l}4267.95 \\
4207.72\end{array}$ \\
\hline Weighted sum & $\begin{array}{l}O b j_{c} \\
O b j_{f}\end{array}$ & $\begin{array}{l}3890 \\
7310 \\
\end{array}$ & $\begin{array}{l}0.1818(0.4453) \\
0.0909(0.2957)\end{array}$ & $\begin{array}{l}4209.70 \\
4218.23\end{array}$ \\
\hline $\begin{array}{l}\text { Lexicographic } \\
\text { optimization }\end{array}$ & $\begin{array}{l}O b j_{c} \\
O b j_{f}\end{array}$ & ${ }^{3890} \wedge$ & $\begin{array}{c}0.1818 \text { (0.4453) } \\
\text { Vo feasible solutior }\end{array}$ & $\begin{array}{l}4204.30 \\
\text { found }\end{array}$ \\
\hline
\end{tabular}

[*] in the case of $O \mathrm{Obj}_{f}$ the standard deviation within the different GAPs is reported inside the parenthesis

In the scenarios where lexicographic optimization is able to obtain a feasible solution, this solution proposes a better bound for the nadir value than the weighted sum or single objective optimization. Then, in general, the biased weighted sum was able to improve the lower bounds of the nadir values of the single objective optimization except for the $\mathrm{Obj}_{f}$ in the undemanding scenario with classified 
waste. Table 3 reports the estimated ideal and nadir values for each objective in each scenario.

Table 3 Estimated ideal and nadir value of each scenario

\begin{tabular}{lcrr}
\hline Scenario & Objective & Ideal value & Nadir value \\
\hline \multicolumn{4}{c}{ Scenarios with unclassified waste } \\
\hline Normal & $O b j_{c}$ & 3880 & 5710 \\
scenario & $O b j_{f}$ & 0.1042 & 0.1819 \\
\hline Demanding & $O b j_{c}$ & 4710 & 8040 \\
scenario & $O b j_{f}$ & 0.1193 & 0.1932 \\
\hline Undemanding & $O b j_{c}$ & 3140 & 7230 \\
scenario & $O b j_{f}$ & 0.0833 & 0.1061 \\
\hline \multicolumn{4}{c}{ Scenarios with classified waste } \\
\hline Normal & $O b j_{c}$ & 4800 & 9080 \\
scenario & $O b j_{f}$ & 0.1240 & 0.1932 \\
\hline Demanding & $O b j_{c}$ & 5640 & 11180 \\
scenario & $O b j_{f}$ & 0.1477 & 0.2159 \\
\hline Undemanding & $O b j_{c}$ & 3890 & 7310 \\
scenario & $O b j_{f}$ & 0.0900 & 0.1818 \\
\hline
\end{tabular}

Tables 4 and 5 summarize the solutions obtained with AUGMECON for the unclassified and classified scenarios respectively with the following information: the values of the objectives, the excecution times and whether these solutions are dominated by another solution (D) or not (Non-D). A solution is dominated by another solution when this last one has a better value in at least one of the optimization criteria and not a worse value in the rest of the optimization criteria. To determine the dominance of each of these multiobjective solutions, they are compared with the other multiobjective solutions but also with the solutions for approximating the range of the objectives from Tables 1 and 2. AUGMECON guarantees obtaining a non-dominated solution if and only if the problem is solved to optimality. As it can be seen from the Tables 4 and 5 , none of the solutions were solved to optimality since they were aborted due to time limit, which is again probably related with the complexity of the underlying facility location problem. Clearly, scenarios with classified waste are more challenging for AUGMECON. In these scenarios, the method was able to find fewer solutions than in scenarios with unclassified waste. This may be related to the fact that source separated scenarios have a larger number of integer variables $(|H|=2)$, which is usually associated with the complexity of the problem [15].

Figures 3-5 graphically shows the computed solutions for the normal, demanding, and undemanding scenarios with unclassified waste, respectively. Figures 6 and 7 graphically shows the computed solutions for the normal and undemanding scenarios with unclassified waste, respectively.
Table 4 Multiobjective solutions for the unclassified scenarios

\begin{tabular}{|c|c|c|c|c|}
\hline $\begin{array}{l}\text { Solution } \\
\text { id }\end{array}$ & $\boldsymbol{O} b j_{c}$ & $\left.\boldsymbol{O b j _ { f }} \boldsymbol{l}^{*}\right)$ & $\begin{array}{c}\text { Execution } \\
\text { time (s) }\end{array}$ & Dominance \\
\hline \multicolumn{5}{|c|}{ Normal scenario } \\
\hline 1 & 4800 & $0.1288(0.3135)$ & 4207.63 & Non-D \\
\hline 2 & 4900 & $0.1117(0.2938)$ & 4204.45 & Non-D \\
\hline 3 & 5080 & $0.1079(0.2832)$ & 4202.89 & Non-D \\
\hline 4 & 5230 & $0.1061(0.2811)$ & 4203.36 & Non-D \\
\hline 5 & 5360 & $0.1061(0.2811)$ & 4206.07 & D \\
\hline 6 & 5510 & $0.1042(0.2790)$ & 4203.56 & Non-D \\
\hline \multicolumn{5}{|c|}{ Demanding scenario } \\
\hline 1 & 5700 & $0.1307(0.3212)$ & 4208.45 & Non-D \\
\hline 2 & 6020 & $0.1250(0.3061)$ & 4204.72 & Non-D \\
\hline 3 & 7120 & $0.1269(0.2898)$ & 4207.63 & D \\
\hline 4 & 7400 & $0.1269(0.2898)$ & 4205.05 & D \\
\hline 5 & 7830 & $0.1288(0.2981)$ & 4210.22 & $\mathrm{D}$ \\
\hline 6 & 8190 & $0.1288(0.2783)$ & 4207.14 & D \\
\hline 7 & 9320 & $0.1250(0.2452)$ & 4208.45 & $\mathrm{D}$ \\
\hline \multicolumn{5}{|c|}{ Undemanding scenario } \\
\hline 1 & 3500 & $0.1022(0.2935)$ & 4200.50 & Non-D \\
\hline 2 & 3630 & $0.1042(0.2923)$ & 4204.91 & D \\
\hline 3 & 3690 & $0.0928(0.2762)$ & 4210.39 & Non-D \\
\hline 4 & 3790 & 0.0909 (0.2740) & 4203.47 & Non-D \\
\hline 5 & 3850 & 0.1004 (0.2815) & 4208.70 & D \\
\hline 6 & 3890 & $0.0890(0.2647)$ & 4229.86 & Non-D \\
\hline 7 & 4190 & 0.0852 (0.2599) & 4206.56 & Non-D \\
\hline
\end{tabular}

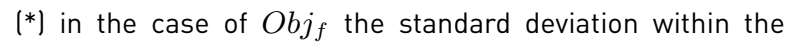
different GAPs is reported inside the parenthesis

Table 5 Multiobjective solutions for the classified scenarios

\begin{tabular}{ccccc}
\hline $\begin{array}{c}\text { Solution } \\
\text { id }\end{array}$ & $\boldsymbol{O} b j_{c}$ & $\boldsymbol{O} b j_{f} \boldsymbol{}^{*}$ ) & $\begin{array}{c}\text { Execution } \\
\text { time (s) }\end{array}$ & Dominance \\
\hline \multicolumn{5}{c}{ Normal scenario } \\
\hline 1 & 5290 & $0.1761(0.4261)$ & 4229.75 & Non-D \\
2 & 5410 & $0.1647(0.4004)$ & 4297.73 & Non-D \\
\hline \multicolumn{5}{c}{ Demanding scenario } \\
\hline 1 & 5580 & $0.1932(0.3959)$ & 4248.02 & Non-D \\
2 & 7990 & $0.1979(0.3586)$ & 4250.3 & D \\
\hline \multicolumn{5}{c}{ Undemanding scenario } \\
\hline 1 & 6490 & $0.1004(0.3469)$ & 4260.91 & Non-D \\
\hline
\end{tabular}

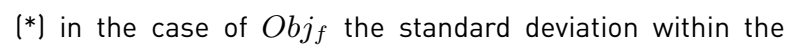
different GAPs is reported inside the parenthesis

The plot of the demanding scenario with classified waste is not presented since the Pareto front was only composed by two solutions. For the sake of clarity, in general single objective solutions are not presented since the magnitude of the objective that is not optimized affects the scale of the graphic and are not part of the Pareto front, except 
for the undemanding scenario with classified waste in which one of these single objective solution is part of the estimated Pareto front.

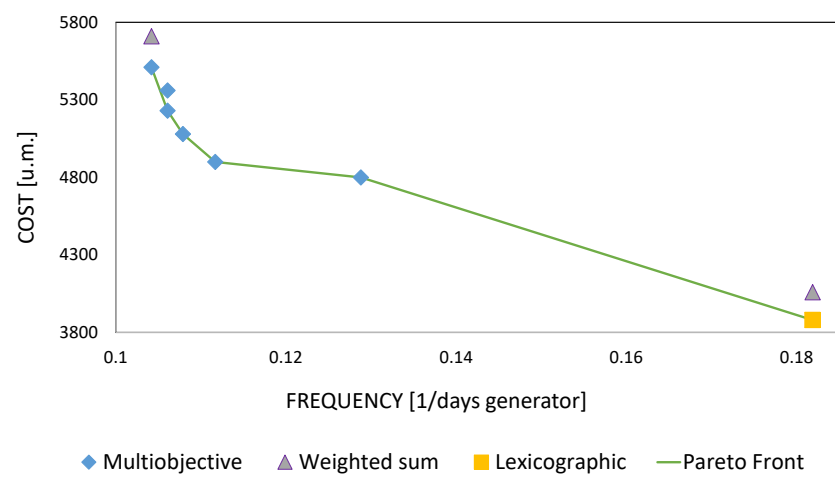

Figure 3 Solutions for the normal scenario with unclassified waste

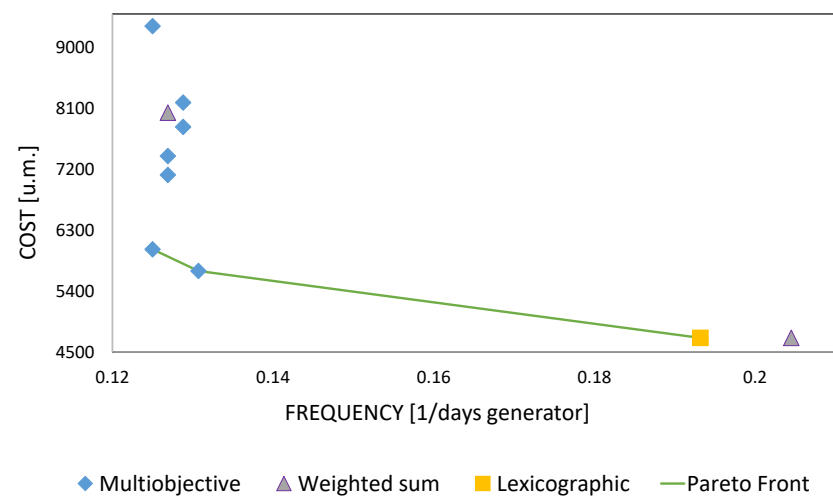

Figure 4 Solutions for the demanding scenario with unclassified waste

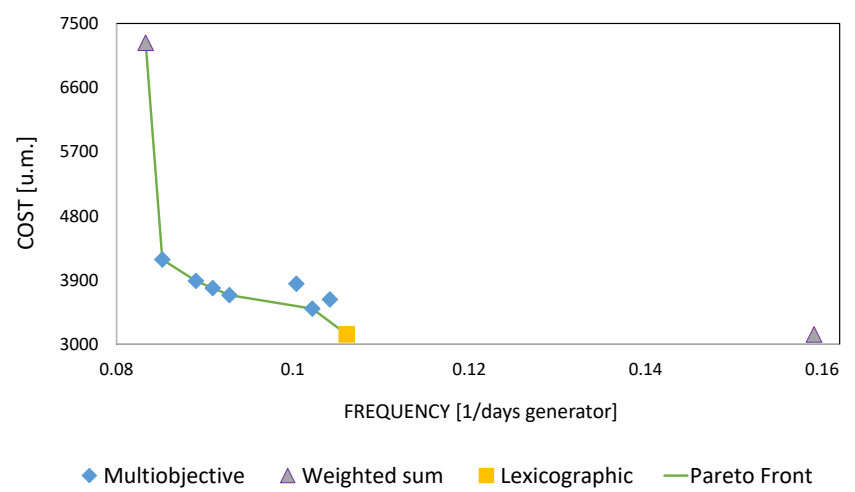

Figure 5 Solutions for the undemanding scenario with unclassified waste

Although the model was able to solve different scenarios, the execution times are quite large. For solving larger instances, heuristics and metaheuristics methods can be implemented. In these cases, the presented model can be used for validating the model in small instances.

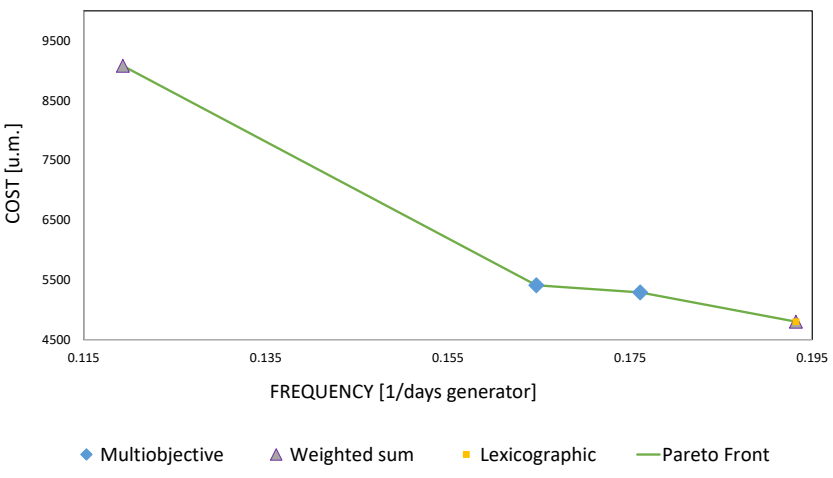

Figure 6 Solutions for the normal scenario with classified waste

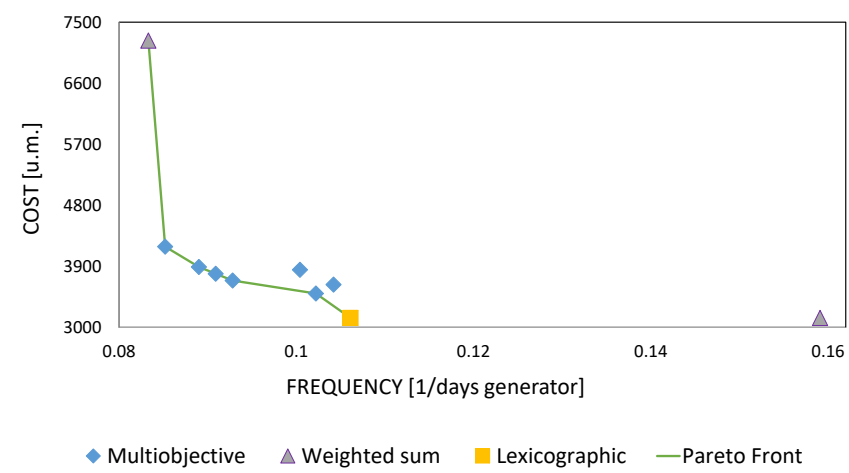

Figure 7 Solutions for the undemanding scenario with classified waste

\subsection{Analysis of results in terms of the problem}

The obtained solutions allowed to obtain a distribution of waste bins in a neighborhood that aims to minimize the installment cost and enhance the autonomy of the bins, i.e., the number of days that a bin can remain without been emptied by the collection vehicle. The autonomy objective is of special relevance for a country as Argentina that has a remarkably high logistic costs [9], specially due to the high salaries that have the Argentinian drivers [44]. Despite considering the minimization of installment and collection costs, the proposed distribution also ensures that none of the generator do not have to travel more than $250 \mathrm{~m}$ which is in line with the suggestions in [45] to enhance accessibility to the system.

Finally, this model can be used to develop a collection network in the target city of Bahía Blanca to migrate from the door-to-door collection to a community bins based system. In order to perform a smoother transition between the two collection systems, and considering that Bahía Blanca does not perform source separation of waste yet, the City Hall can implement a community bins network without classification first and then, when the citizens get used to this system, implement source separation . 


\section{Conclusions and future work}

Municipal Solid Waste management is a complex issue for local governments that usually are in charge of collection. The research reported in this article focused on the initial stage of the reverse logistic chain of Municipal Solid Waste. Particularly, a mathematical formulation for determining the location of garbage accumulation points in an urban area while considering two objectives related to the expenses of the system is proposed. The optimized objectives are the minimization of the investment cost required for installing the bins and the required frequency of visits of the collection vehicle to empty the bins which is related to the routing cost. This last objective is important for decision makers in countries that have particularly high routing cost, as is the case of Argentina. Moreover, this model is applied to real scenarios of the Argentinian city of Bahía Blanca, where the government is interested in migrating from the current door-to-door collection to a community bins based system. The scenarios include instances with unsorted waste collection, which is the current situation of the city and thus can be implemented more easily, and with source classified waste in two different fractions, dry and humid waste, which can be implemented in a second phase when the citizens are already accustomed to community bins.

The solutions for the problem were obtained applying the augmented $\varepsilon$-constraint method (AUGMECON). For this purpose, three variations for finding the efficient range of the objectives (which is an input of the AUGMECON) are tested: single objective optimization, lexicographic optimization and a recently proposed approach based on the weighted sum. While lexicographic optimization was not able to obtain feasible solutions for all the scenarios, mainly because of the complexity of the optimization problem, the approach based on the weighted sum was able to estimate the efficient range in all the analyzed scenarios. Although the scenarios with classified waste were much more challenging than the scenarios with unsorted waste for the resolution method, the proposed approach was able to find a set of feasible solutions in all the scenarios. Another important conclusion is that this work was mainly performed with free software to obtain and process geographic information (OpenStreetMap, R packages and QGIS). This represents an asset for local authorities of developing countries as Argentina that generally have a short budget to incorporate smart cities initiatives in public services. Only the optimizer solver, CPLEX, requires a paid license.

The main lines for future work are focused on continue improving the proposed exact approach to be able to find a larger set of multiobjetive solutions in complex scenarios, such as the scenarios with source classified waste.
Moreover, these more complex scenarios may also require the application of heuristic algorithms. Therefore, another important research line is to design competitive heuristics approaches that can be validated with the proposed exact approach for small instances. Another relevant line to research is to continue experimenting different methods for improving the estimation of the ranges of the objectives within the Pareto front in computationally challenging problems, since the quality of these approximations can have an impact on the performance of the multiobjective exact approaches. Finally, similarly to the variations of the generations rate that were considered is this paper, a sensitivity analysis over the maximum allowable walking distance or different spatial distribution of the generators can be performed.

\section{Acknowledgements}

We would like to thank the anonymous reviewers for their insightful comments on the paper that led us to an improvement of this work.

This research was partially funded by Ministerio de Economía, Industria y Competitividad, Gobierno de España, and European Regional Development Fund grant numbers TIN2016-81766-REDT (http://cirti.es), and TIN2017-88213-R (http://6city.lcc.uma.es).

European Union's Horizon 2020 research and innovation programme under the Marie Skłodowska-Curie grant agreement No 799078.

Universidad de Málaga, Campus Internacional de Excelencia Andalucía TECH.

\section{References}

[1] H. Chourabi and et al., “Understanding smart cities: An integrative framework," in $201245^{\text {th }}$ Hawaii international conference on system sciences. IEEE, 2012, pp. 2289-2297.

[2] R. Massobrio, J. Toutouh, S. Nesmachnow, and E. Alba, "Infrastructure deployment in vehicular communication networks using a parallel multiobjective evolutionary algorithm," International Journal of Intelligent Systems, vol. 32, no. 8, pp. 801-829, 2017.

[3] D. Peña, A. Tchernykh, S. Nesmachnow, R. Massobrio, A. Feoktistov, I. Bychkov, G. Radchenko, A. Y. Drozdov, and S. N. Garichev, "Operating cost and quality of service optimization for multi-vehicle-type timetabling for urban bus systems," Journal of Parallel and Distributed Computing, 2018.

[4] A. Solanas and et al., "Smart health: a context-aware health paradigm within smart cities," IEEE Communications Magazine, vol. 52, no. 8, pp. 74-81, 2014.

[5] C. Calvillo, A. Sánchez, and J. Villar, “Energy management and planning in smart cities," Renewable and Sustainable Energy Reviews, vol. 55, pp. 273-287, 2016.

[6] D. Hoornweg and P. Bhada-Tata, "What a waste: a Global Review of Solid Waste Management," World Bank, Washington, United States, Urban Development Series Knowledge Papers 15, 2012.

[7] D. G. Rossit, S. Nesmachnow, and J. Toutouh, "Municipal solid waste management in smart cities: facility location of community bins," in 
Ibero-American Congress of Smart Cities ICSC-CITIES 2018. CCIS, vol. 978. Springer, 2019, pp. 102-115.

[8] F. Bonomo, G. Durán, F. Larumbe, and J. Marenco, "A method for optimizing waste collection using mathematical programming: a Buenos Aires case study," Waste Management \& Research, vol. 30 , no. 3, pp. 311-324, 2012.

[9] D. Broz, D. A. Rossit, D. G. Rossit, and A. Cavallin, "The Argentinian forest sector: opportunities and challenges in supply chain management," Uncertain Supply Chain Management, vol. 6, no. 4, pp. 375-392, 2018.

[10] M. Martin, I. D. Williams, and M. Clark, "Social, cultural and structural influences on household waste recycling: A case study," Resources, conservation and recycling, vol. 48, no. 4, pp. 357-395, 2006.

[11] J. Toutouh, D. G. Rossit, and S. Nesmachnow, "Computational intelligence for locating garbage accumulation points in urban scenarios," in International Conference on Learning and Intelligent Optimization LION 12 2018. LNCS, vol. 11353. Springer, 2018, pp. 411-426.

[12] G. Cornuéjols, R. Sridharan, and J. M. Thizy, "A comparison of heuristics and relaxations for the capacitated plant location problem," European Journal of Operational Research, vol. 50, no. 3, pp. 280-297, 1991.

[13] R. Vijay, A. Gautam, A. Kalamdhad, A. Gupta, and S. Devotta, "Gis-based locational analysis of collection bins in municipal solid waste management systems," Journal of Environmental Engineering and Science, vol. 7, no. 1, pp. 39-43, 2008.

[14] W. P. Adams, R. J. Forrester, and F. W. Glover, "Comparisons and enhancement strategies for linearizing mixed 0-1 quadratic programs," Discrete Optimization, vol. 1, no. 2, pp. 99-120, 2004.

[15] F. Glover, "Improved linear integer programming formulations of nonlinear integer problems," Management Science, vol. 22, no. 4, pp. 455-460, 1975.

[16] F. Glover, "An improved MIP formulation for products of discrete and continuous variables," Journal of Information and Optimization Sciences, vol. 5, no. 1, pp. 69-71, 1984.

[17] L. Tralhão, J. Coutinho, and L. Alçada, "A multiobjective modeling approach to locate multi-compartment containers for urban-sorted waste," Waste Management, vol. 30, no. 12, pp. 2418-2429, 2010.

[18] J. Coutinho, L. Tralhão, and L. Alçada, "A bi-objective modeling approach applied to an urban semi-desirable facility location problem," European Journal of Operational Research, vol. 223, no. 1, pp. 203-213, 2012.

[19] J. J. Kao and T. I. Lin, "Shortest service location model for planning waste pickup locations," Journal of the Air \& Waste Management Association, vol. 52, no. 5, pp. 585-592, 2002.

[20] V. C. Hemmelmayr, K. F. Doerner, R. F. Hartl, and D. Vigo, “Models and algorithms for the integrated planning of bin allocation and vehicle routing in solid waste management," Transportation Science, vol. 48, no. 1, pp. 103-120, 2013.

[21] H. Y. Lin, Z. P. Tsai, G. H. Chen, and J. J. Kao, "A model for the implementation of a two-shift municipal solid waste and recyclable material collection plan that offers greater convenience to residents," Journal of the Air \& Waste Management Association, vol. 61, no. 1, pp. 55-62, 2011.

[22] G. Ghiani, D. Laganà, E. Manni, and C. Triki, "Capacitated location of collection sites in an urban waste management system," Waste Management, vol. 32, no. 7, pp. 1291-1296, 2012.

[23] G. Ghiani, A. Manni, E. Manni, and M. Toraldo, "The impact of an efficient collection sites location on the zoning phase in municipal solid waste management," Waste Management, vol. 34, no. 11, pp. 1949-1956, 2014.

[24] D. Purkayastha, M. Majumder, and S. Chakrabarti, "Collection and recycle bin location-allocation problem in solid waste management: A review," Pollution, vol. 1, no. 2, pp. 175-191, 2015.

[25] P. Di Felice, "Integration of spatial and descriptive information to solve the urban waste accumulation problem," Procedia-Social and Behavioral Sciences, vol. 147, pp. 182-188, 2014.

[26] N. B. Chang and Y. L. Wei, "Siting recycling drop-off stations in urban area by genetic algorithm-based fuzzy multiobjective nonlinear integer programming modeling," Fuzzy Sets and Systems, vol. 114, no. 1, pp. 133-149, 2000.

[27] T. M. Hua, T. K. Nguyen, H. Van, and D. Thi, "Towards a decision support system for municipal waste collection by integrating geographical information system map, smart devices and agent-based model," in Seventh Symposium on Information and Communication Technology. Ho Chi Minh, Vietnam: ACM, 2016, pp. 139-146.

[28] F. Bertero, “Optimización de recorridos en ciudades. Una aplicación al sistema de recolección de residuos sólidos urbanos en el Municipio de Concordia," Master's thesis, Faculty of Exact Sciences and Engineering, Universidad Nacional de Rosario, Rosario, Argentina, september 2015.

[29] M. Bianchetti, G. Duran, I. Koch, and J. Marenco, "Algoritmos de zonificación para el problema de la recolección de residuos urbanos: el caso de estudio de una ciudad argentina," Revista Ingeniería de Sistemas, vol. 21, 2017.

[30] G. Braier, G. Durán, J. Marenco, and F. Wesner, “An integer programming approach to a real-world recyclable waste collection problem in argentina," Waste Management \& Research, vol. 35, no. 5, pp. 525-533, 2017.

[31] D. G. Rossit, F. Tohmé, M. Frutos, and D. Broz, “An application of the augmented $\varepsilon$-constraint method to design a municipal sorted waste collection system," Decision Science Letters, vol. 6, no. 4, pp. 323-336, 2017.

[32] L. Schejtman and N. Irurita, "Diagnóstico sobre la gestión de los residuos sólidos urbanos en municipios de la Argentina," Centro de Implementación de Políticas Públicas para la Equidad y el Crecimiento, Technical report 103, September 2012, https://www. cippec.org/wp-content/uploads/2017/03/1552.pdf.

[33] G. Mavrotas, "Effective implementation of the $\varepsilon$-constraint method in multi-objective mathematical programming problems," Applied Mathematics and Computation, vol. 213, no. 2, pp. 455-465, 2009.

[34] G. Mavrotas and K. Florios, "An improved version of the augmented $\varepsilon$-constraint method (AUGMECON2) for finding the exact pareto set in multi-objective integer programming problems," Applied Mathematics and Computation, vol. 219, no. 18, pp. 9652-9669, 2013.

[35] Y. Y. Haimes, L. S. Lasdon, and D. A. Wismer, "On a bicriterion formulation of the problems of integrated system identification and system optimization," IEEE transactions on systems, man, and cybernetics, vol. 1, no. 3, pp. 296-297, 1971.

[36] M. Ehrgott and D. M. Ryan, "Constructing robust crew schedules with bicriteria optimization," Journal of Multi-Criteria Decision Analysis, vol. 11, no. 3, pp. 139-150, 2002.

[37] R. M. Beeson, "Optimization with respect to multiple criteria," Ph.D. dissertation, University of Southern California, United States of America, June 1972.

[38] D. G. Rossit, "Desarrollo de modelos y algoritmos para optimizar redes logísticas de residuos sólidos urbanos," PhD thesis, Department of Engineering, Universidad Nacional del Sur, Bahía Blanca, Argentina, september 2018.

[39] Planta Piloto de Ingeniería Química UNS-CONICET, “Análisis estadístico de los residuos sólidos domiciliarios de Bahía Blanca," February 2013.

[40] E. Pettigiani, A. Muzlera, and S. Antonini, “Caracterización de residuos sólidos urbanos domiciliarios en Unquillo, Córdoba," in III Jornadas Nacionales GIRSU 2013. Rawson, Argentina: Instituto Nacional de Tecnología Industrial, 2013, pp. 5-17.

[41] Dirección Provincial de Estadística de la Provincia de Buenos Aires, Argentina, "Censo 2010 Provincia de Buenos Aires Resultados Definitivos por Partido," 2010, http://www.estadistica.ec.gba.gov.ar/ dpe/Estadistica/CENSO2010\%20REVISION/librocenso2010.pdf.

[42] M. J. A. Eugster and T. Schlesinger, "osmar: OpenStreetMap and R," The R Journal, vol. 5, no. 1, pp. 53-63, 2013.

[43] Ministerio de Interior y Transporte, Argentina, "Gestión integral de residuos sólidos urbanos," https://www.mininterior.gov.ar/ municipios/pdfs/SAM_03_residuos_solidos.pdf.

[44] E. Benes and B. F. Milmanda, "El nuevo liderazgo sindical en la argentina postneoliberal: el caso del gremio de camioneros," Desarrollo Económico: Revista de Ciencias Sociales, pp. 31-62, 2012. 
[45] L. Parrot, J. Sotamenou, and B. K. Dia, “Municipal solid waste management in africa: Strategies and livelihoods in yaoundé, cameroon," Waste management, vol. 29, no. 2, pp. 986-995, 2009.

[46] S. Nesmachnow, D. G. Rossit, and J. Toutouh, "Comparison of multiobjective evolutionary algorithms for prioritized urban waste collection in Montevideo, Uruguay," Electronic Notes in Discrete Mathematics, vol. 69, pp. 93-100, 2018.

[47] E. Orsi and S. Nesmachnow, "Smart home energy planning using loT and the cloud," in URUCON IEEE, October 2017, pp. 1-4.

[48] D. G. Rossit, D. Broz, D. A. Rossit, M. Frutos, and F. Tohmé, "Una herramienta logística para la localización de contenedores de residuos separados en origen," in Avances en Gestión Integral de Residuos Sólidos Urbanos 2014-15, N. M. Mazzeo and A. M. M. Muzlera Klappenbach, Eds. Buenos Aires, Argentina: Instituto Nacional de Tecnología Industrial, 2015, pp. 50-69. 